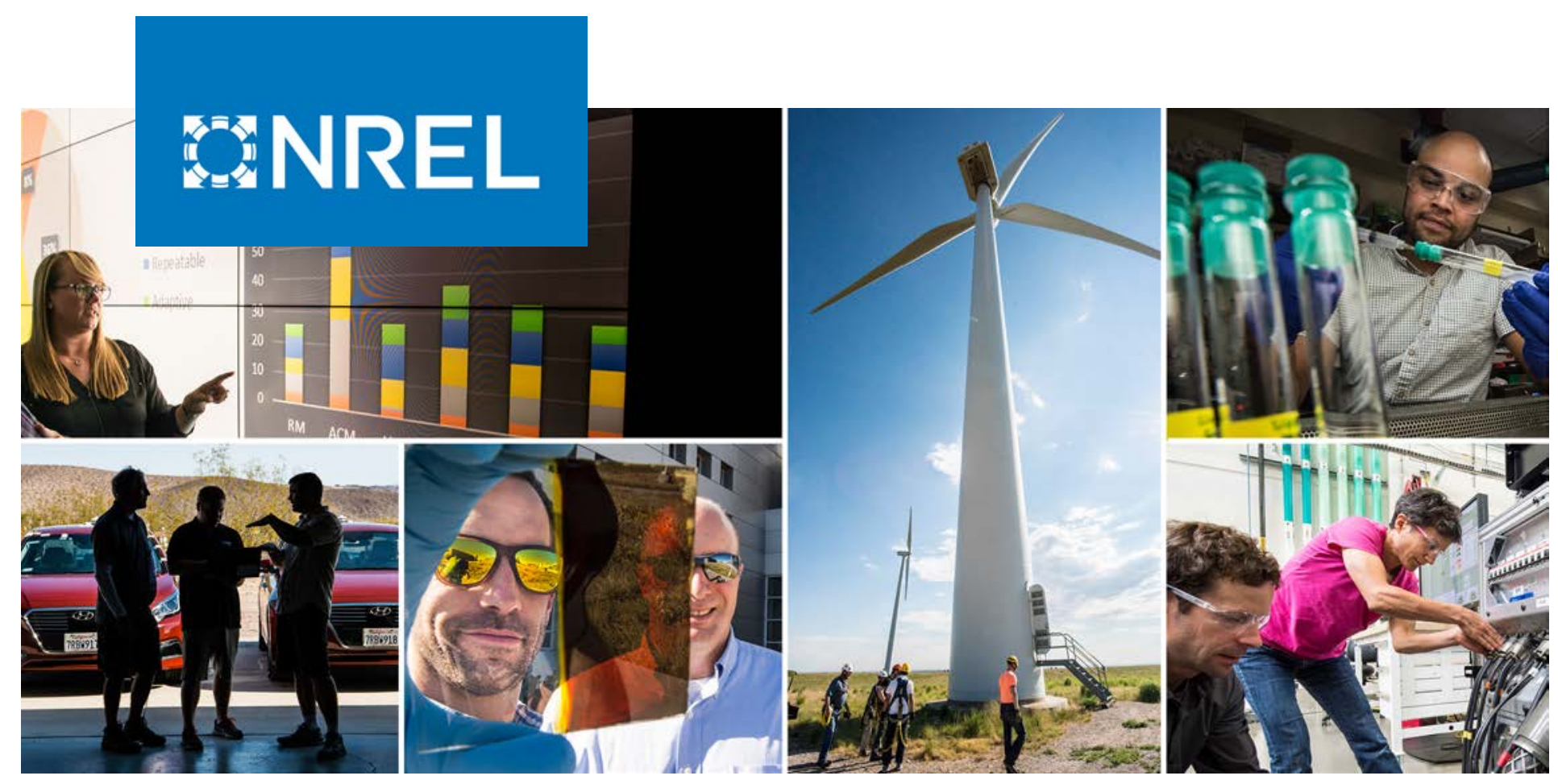

\title{
Solar Buyer's Markets: Unlocking Lower Photovoltaic and Battery Prices on Online Quote Platforms
}

Eric O'Shaughnessy and Robert Margolis

National Renewable Energy Laboratory

NREL is a national laboratory of the U.S. Department of Energy

Office of Energy Efficiency \& Renewable Energy

Operated by the Alliance for Sustainable Energy, LLC

This report is available at no cost from the National Renewable Energy Laboratory (NREL) at www.nrel.gov/publications.
Technical Report

NREL/TP-6A20-72172

November 2018 


\title{
GNREL
}

\section{Solar Buyer's Markets: Unlocking}

Lower Photovoltaic and Battery Prices on Online Quote Platforms

\author{
Eric O'Shaughnessy and Robert Margolis
}

National Renewable Energy Laboratory

\section{Suggested Citation}

O'Shaughnessy, Eric, and Robert Margolis. 2018. Solar Buyer's Markets: Unlocking Lower Photovoltaic and Battery Prices on Online Quote Platforms. Golden, CO:

National Renewable Energy Laboratory. NREL/TP-6A20-72172.

https://www.nrel.gov/docs/fy19osti/72172.pdf.

NREL is a national laboratory of the U.S. Department of Energy Office of Energy Efficiency \& Renewable Energy Operated by the Alliance for Sustainable Energy, LLC

This report is available at no cost from the National Renewable Energy Laboratory (NREL) at www.nrel.gov/publications.

Contract No. DE-AC36-08GO28308
Technical Report

NREL/TP-6A20-72172

November 2018

National Renewable Energy Laboratory 15013 Denver West Parkway Golden, CO 80401

303-275-3000 • www.nrel.gov 


\section{NOTICE}

This work was authored by the National Renewable Energy Laboratory, operated by Alliance for Sustainable Energy, LLC, for the U.S. Department of Energy (DOE) under Contract No. DE-AC36-08G028308. Funding provided by U.S. Department of Energy Office of Energy Efficiency and Renewable Energy Solar Energy Technologies Office. The views expressed herein do not necessarily represent the views of the DOE or the U.S. Government.

This report is available at no cost from the National Renewable Energy Laboratory (NREL) at www.nrel.gov/publications.

U.S. Department of Energy (DOE) reports produced after 1991 and a growing number of pre-1991 documents are available free via www.OSTI.gov.

Cover Photos by Dennis Schroeder: (clockwise, left to right) NREL 51934, NREL 45897, NREL 42160, NREL 45891, NREL 48097, NREL 46526.

NREL prints on paper that contains recycled content. 


\section{Acknowledgements}

This work was supported by the Solar Energy Technologies Office at the U.S. Department of Energy. The authors would like to thank Kristen Ardani (NREL) and Allison Mond (GTM Research) for their thoughtful review of this work. The authors would also like to thank Max Aram, Andrew Bare, and Kyle Cherrick of Pick My Solar for their collaboration on this project, as well as Mike Meshek (NREL) and Jarett Zuboy (consultant) for editorial support. 


\section{Executive Summary}

Most residential solar photovoltaic (PV) and battery customers obtain system installation price quotes directly from installers. Because of the time and effort required, most customers select an installer after obtaining only a few quotes, or they forego adoption if an acceptable quote is not obtained. However, an increasing number of PV and battery customers are obtaining numerous quotes more quickly and easily via online quote platforms. In the platform model, a customer provides information about the home and desired system characteristics to a quote "aggregator," who conveys this information to a network of installers. Interested installers submit bids to the online quote platform, where the customer can then compare bids in a common format. Previous research by the National Renewable Energy Laboratory - using data from the EnergySage platform - suggested that competition spurred by quote platforms reduces offered PV prices.

In this report, we analyze the effects of quote platform use on PV prices by studying prices on the Pick My Solar platform. We find that Pick My Solar prices are lower, on average, than prices from quotes obtained directly from installers. Together with the results from our study using EnergySage data, these findings indicate that quote platforms in general - rather than a particular platform - are associated with reduced PV prices. By using quote platforms rather than directly soliciting quotes from installers, PV customers might save roughly $\$ 0.20 / \mathrm{W}-\$ 0.40 / \mathrm{W}$, which is equivalent to $\$ 1,000-\$ 2,000$ in savings for a typical 5-kW residential PV system. Despite the savings potential, only about $3 \%$ of residential PV sales currently occur through online platforms - though more customers use platforms without adopting PV, and some customers may use platforms to learn about PV prices before accepting a quote received directly from an installer. Continued growth of platform use could yield PV price reductions for at least two reasons. First, it could push the average PV price point toward lower platform prices. Second, it could produce spillover effects by forcing reductions in quotes outside of platforms. For instance, national-scale installers - which have not historically used quote platforms - may begin to offer lower prices if greater numbers of prospective customers begin to use the platforms.

Our study also represents one of the first explorations of installed battery price data. We find evidence that battery prices from quote platforms are lower than market-wide prices, though the sample size is small and further research is required. In addition, the data suggest that installed battery prices are not falling as quickly as battery hardware costs, while installed battery prices may be more standardized than installed PV prices. Collectively, these results suggest that quote platforms may provide a pathway for ongoing PV and battery price reductions. Various approaches could increase the use of platforms and thus accelerate the associated price reductions and deployment. These approaches include forming strategic partnerships between platforms and trusted third parties (e.g., utilities, local government entities, environmental organizations, and Solarize campaigns), building consumer confidence in online platforms, using platform features to enhance PV market transparency, and offering quality guarantees through platforms.

Finally, quote platforms have potential supply-side impacts as well. The greater competition and reduced prices likely decrease installer profit margins. In addition, increased platform activity might shift market shares from high-volume national-scale installers to local installers, while platform installer eligibility criteria may present a barrier to market entry for new and very small-scale installers. 


\section{Table of Contents}

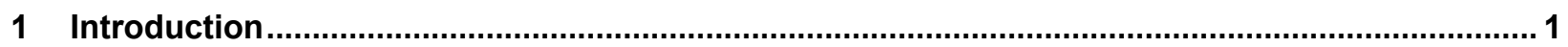

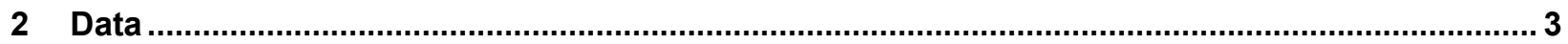

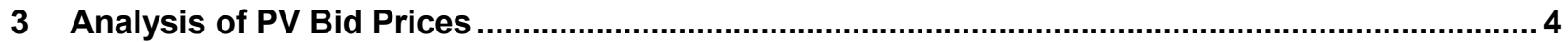

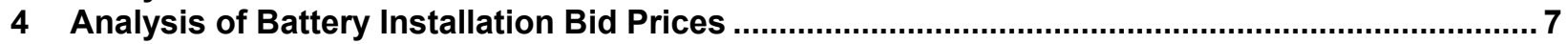

5 Pathways toward Increased Use of Quote Platforms ....................................................... 11

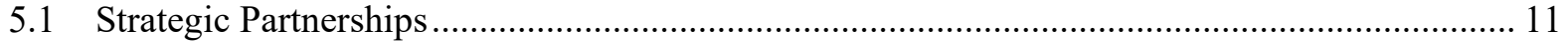

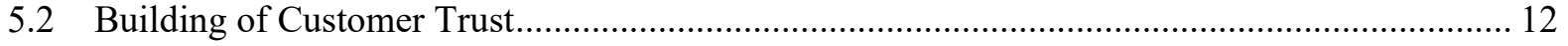

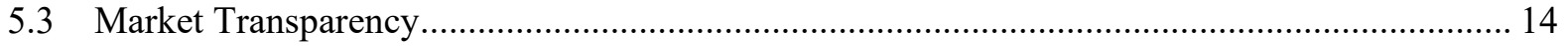

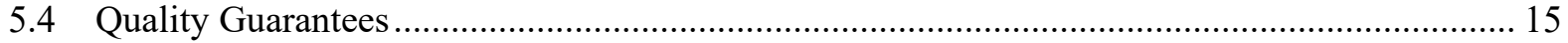

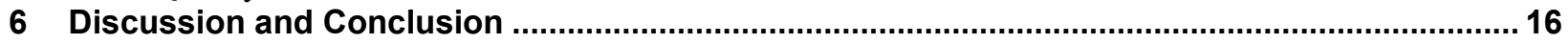

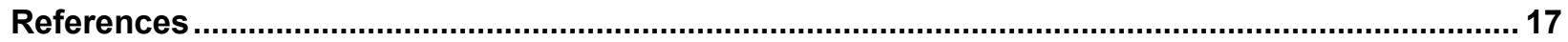




\section{List of Figures}

Figure 1. Basic quote platform structure ...................................................................................... 1

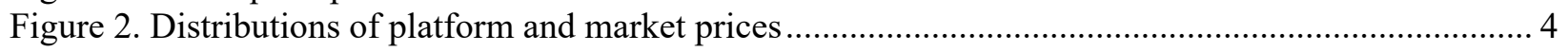

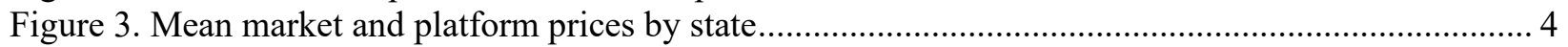

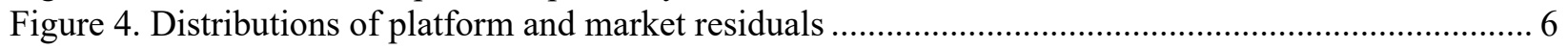

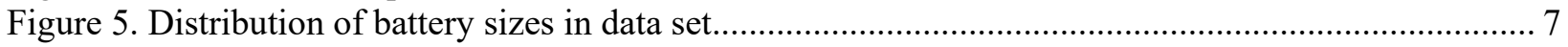

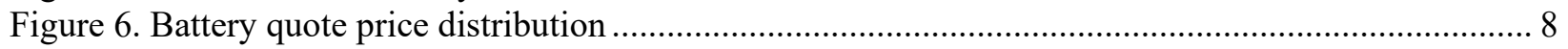

Figure 7. Battery quote price distributions by quarter ........................................................................ 9

Figure 8. Pick My Solar battery quote distributions versus GTM low installed price estimate .................. 9

Figure 9. Quote platform/utility partnership structure …................................................................... 12

\section{List of Tables}

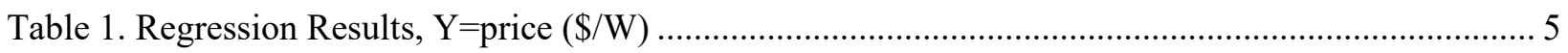

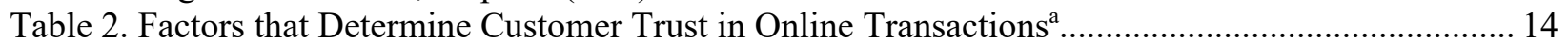




\section{Introduction}

Most U.S. residential solar photovoltaic (PV) customers procure PV by obtaining quotes directly from PV installers. The quote collection process can be burdensome: prospective customers must invest time and effort to identify installers, host site visits, compile paperwork, and complete numerous steps before obtaining a cost quote. Prospective PV customers generally minimize quote collection costs by making a decision after obtaining typically fewer than three quotes (Moezzi et al. 2017). Customers with few quotes have less bargaining power, given that such customers cannot easily refuse a high-priced quote if few or no alternative quotes are available. As a result, installers may be able to increase profit margins when bidding to customers who receive few quotes. Identifying pathways to reduce quote collection costs and allow customers to obtain more quotes may provide ways to reduce PV prices.

Online quote platforms offer one potential solution. Although only about $3 \%$ of U.S. residential PV systems are currently procured through online quote platforms, ${ }^{1}$ the number of customers procuring PV this way is increasing (Mond 2017). Quote platform designs vary (Leibowicz et al. 2018), but the basic structure is summarized in Figure 1. All quote platforms include a few common steps: (1) a prospective customer submits information about their home and system preferences to the platform administrator or quote "aggregator," (2) the aggregator conveys this information to a network of installers, (3) interested installers submit quotes to the aggregator, and (4) the aggregator posts eligible quotes to an online quote platform, where customers can compare quotes and select the desired installer.

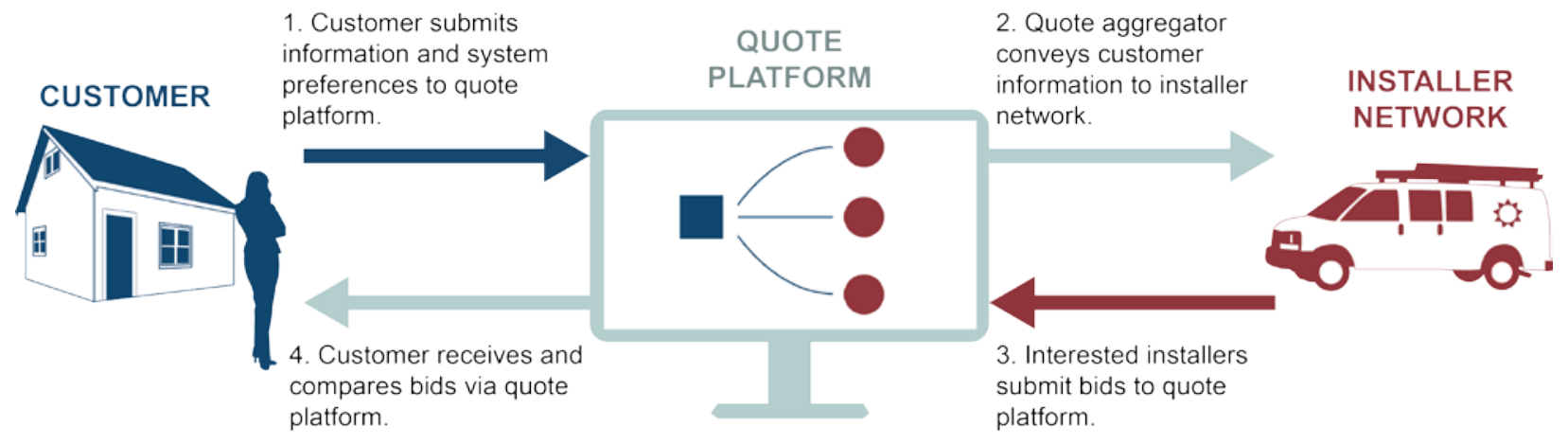

Figure 1. Basic quote platform structure

Quote platforms generally reduce quote collection costs by allowing customers to obtain multiple quotes through a single transaction (Bakos 1997; Brynjolfsson and Smith 2000). In the case of $\mathrm{PV}$, a prospective customer may spend several hours to obtain a single quote directly from an installer but could obtain several quotes from several installers through a single solicitation on a quote platform. Lower quote collection costs mean customers gain more bargaining power on online platforms and should theoretically obtain lower prices (Bakos 1997). O'Shaughnessy and Margolis (2018) find evidence to support this hypothesis using data from the EnergySage quote

\footnotetext{
${ }^{1}$ According to Mond (2017), about 3\% of PV sales occurred on quote platforms in 2017. However, many prospective customers use quote platforms without actually adopting PV, and an unknown number of customers use platforms to learn about PV prices but ultimately accept a quote received directly from an installer.
} 
platform. The study finds that customers on that quote platform obtain lower prices, on average, than customers who obtain quotes directly from installers.

Lower prices on quote platforms could have supply-side as well as demand-side impacts. Lower prices generally imply lower profit margins for installers. Indeed, several installer interviewees in the EnergySage study reported that margins are lower on the EnergySage quote platform (O'Shaughnessy and Margolis 2017). These impacts may be particularly difficult for small installers that operate on tight margins. The effects of lower margins may be partially offset if quote platforms allow installers to increase sales. In other words, quote platforms may reduce per-sale margins but increase total profits if installers can make more sales on platforms than when bidding directly to customers.

Residential PV customers are also increasingly adopting battery-based energy storage systems. According to one survey, about one-third of PV customers are interested in buying batteries (EnergySage 2018). Batteries can increase the value of PV systems by allowing customers to increase the amount of PV output used in the home rather than sold to the grid (O'Shaughnessy et al. 2018). In 2017, residential customers procured around 19 MW of battery capacity (GTM 2017a) and about 2,200 MW of PV capacity (Perea et al. 2017). As they do with PV, customers generally incur quote collection costs while obtaining battery installation cost quotes from installers. Quote platforms may provide similar opportunities for price reductions in battery markets as they do in residential PV markets.

In this report, we analyze the effects of quote platform use on PV prices by building on our previous EnergySage study (O'Shaughnessy and Margolis 2018) using data from Pick My Solar, a quote aggregator whose quote platform has been active since 2015 (Section 3). We also expand the analysis by comparing battery bid prices on the Pick My Solar platform with market-wide prices (Section 4). Note that, because different quote platforms offer different designs and services, prices and products on one platform may not be directly comparable to prices and products on another platform; to protect proprietary platform features, we do not discuss platform design in depth. Finally, based on a literature review, we qualitatively explore ways that quote platform use might be increased so more customers can realize the price benefits of these platforms suggested by our analysis (Section 5). 


\section{Data}

Pick My Solar provided PV and battery quote data for this study. Every PV quote includes a system price quote that can be normalized by system size into units of dollars per watt $(\$ / W)$. Consistent with previous work (Nemet et al. 2017), we drop quotes for less than $\$ 1 / \mathrm{W}$ or greater than $\$ 25 / \mathrm{W}$ as outliers. We also drop systems smaller than $250 \mathrm{~W}$ as possible data-entry errors. These excluded quotes and systems represent less than $1 \%$ of the raw data set.

To compare quote platform prices with broader market prices, we use PV market price data from Lawrence Berkeley National Laboratory's Tracking the Sun (TTS) data set (Barbose and Darghouth 2017). TTS aggregates data from more than 60 PV incentive and interconnection programs around the United States. We use a cleaned subset of TTS data representing customerowned residential systems (O'Shaughnessy 2018). The subset includes only real transaction prices (i.e., it excludes prices that represent appraised values for third-party owned systems). PV prices have varied over time owing to falling costs and across geographic space owing to various factors. To reduce the effects of temporal and spatial price variation, we restrict the Pick My Solar data for the market comparison analyses to more than 8,000 bids made in 2016 and 2017 in states that are also present in the TTS data set, ${ }^{2}$ and we restrict the TTS data to prices for 182,523 systems installed in 2016 and 2017 in states that are also present in the Pick My Solar data set. For the sake of simplicity, we refer to bid prices on the Pick My Solar platform as platform prices and prices from TTS as market prices.

Pick My Solar also provided data on more than 60 battery contracts signed from Q2 2017 to Q1 2018. Each battery quote includes a full installation price and system capacity in kilowatt-hours $(\mathrm{kWh})$, which we use to normalize prices into units of dollars per $\mathrm{kWh}(\$ / \mathrm{kWh})$. We compare these prices against a range of market price estimates developed by GTM (2017b).

\footnotetext{
${ }^{2}$ For proprietary data reasons, precise sample sizes are not provided.
} 


\section{Analysis of PV Bid Prices}

Platform prices were about $\$ 0.41 / \mathrm{W}(10 \%)$ lower, on average, than market prices (Figure 2). About $72 \%$ of platform prices are lower than $\$ 4 / \mathrm{W}$, compared with about $51 \%$ of market prices. Platform prices are lower than market prices in 10 of the 12 states where the platform and market data overlap (Figure 3). Platform prices are slightly higher than market prices in three states, but these differences are based on smaller sample sizes and may not be statistically significant.

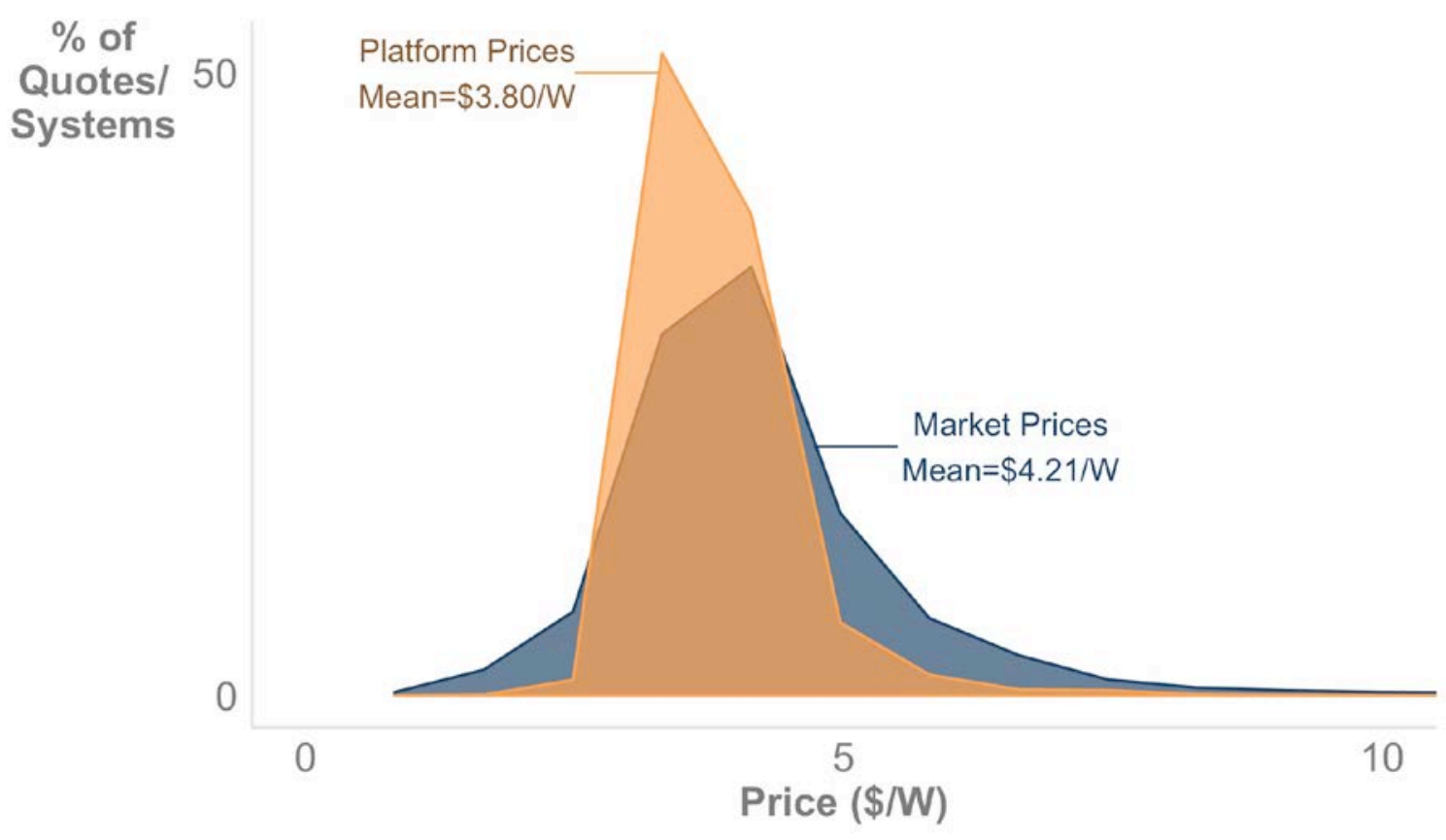

Figure 2. Distributions of platform and market prices

The figure is limited to bids and market prices below $\$ 10 / \mathrm{W}$ for visual simplicity.

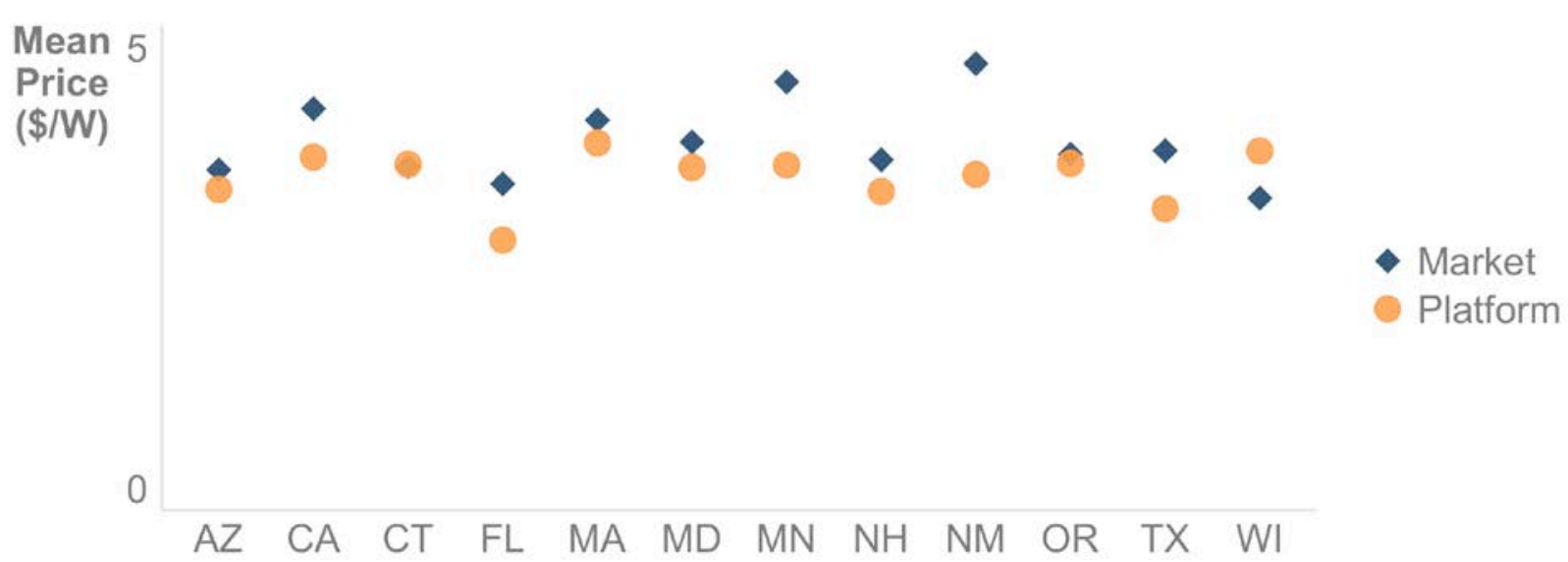

Figure 3. Mean market and platform prices by state 
Some of the disparity between platform and market prices might be attributable to confounding factors. For instance, installers may offer different types of systems on the Pick My Solar platform, such that platform prices cannot be directly compared to market prices. To control for such confounding factors, we estimated the mean difference between platform and market prices using the following regression model:

$$
p=P F \alpha+X \beta+S+Q+\varepsilon
$$

Where $p$ is the bid or installed price, $P F$ is a dummy variable for whether the observation is a platform price $(P F=1)$ or market price $(P F=0), \boldsymbol{X}$ is a matrix of control variables, $S$ is a state fixed effect, $Q$ is a quarter (time) fixed effect, and $\varepsilon$ is an error term. The control variables $(\boldsymbol{X})$ include system size $(\mathrm{kW})$, system size squared, panel efficiency as a proxy for panel quality, and dummy variables for whether the system included a micro-inverter or a direct current optimizer (both premium products). The coefficient $\alpha$ measures the mean difference between platform prices and market prices when controlling for the other factors in the model. The coefficients in $\beta$ measure the effects of the control variables on price.

Table 1 presents the results of the regression model. The model suggests that platform prices are about $\$ 0.31 / \mathrm{W}$ lower, on average, than market prices after controlling for the other factors in the model. In other words, the statistically significantly lower prices on the platform cannot be attributed to differences in system size, equipment type, or temporal or spatial factors. These results - coupled with similar findings based on a different quote platform (O'Shaughnessy and Margolis 2018) —indicate that lower prices are a general characteristic of competitive bidding on quote platforms, not of any one platform in particular.

Table 1. Regression Results, $Y=p r i c e(\$ / W)$

\begin{tabular}{lcc}
\hline Variable & Coefficient & t value \\
\hline platform & -0.31 & $-20.5^{\mathrm{a}}$ \\
system size $(\mathrm{kW})$ & -0.29 & $-76.9^{\mathrm{a}}$ \\
system size squared $\left(\mathrm{kW}^{2}\right)$ & 0.01 & $44.3^{\mathrm{a}}$ \\
panel efficiency & 0.04 & $18.1^{\mathrm{a}}$ \\
DC optimizer & 0.11 & $10.2^{\mathrm{a}}$ \\
micro-inverter & 0.36 & $35.6^{\mathrm{a}}$ \\
intercept & 4.94 & $68.4^{\mathrm{a}}$ \\
\hline \multicolumn{2}{c}{$\mathrm{R}^{2}=0.12,^{\text {a }}$ Effect is statistically significant at $\mathrm{p}<0.01$}
\end{tabular}

The other coefficients in the model accord with theoretical expectations: prices are lower for larger systems owing to economies of scale $(\mathrm{kW})$, but the effect is diminishing $\left(\mathrm{kW}^{2}\right)$; prices are higher for more efficient panels; prices are about $\$ 0.11 / \mathrm{W}$ higher on average for systems that use DC optimizers and about $\$ 0.36 / \mathrm{W}$ higher on average for systems that use micro-inverters.

Figure 4 provides a visualization of the regression results. The figure plots model residuals: the difference between the actual price and the price predicted by the regression model. On average, platform prices were $\$ 0.27 / \mathrm{W}$ lower than predicted by the model, meaning platform prices tend 
to be lower than average after controlling for the model variables. In contrast, market prices were about $\$ 0.02 / \mathrm{W}$ higher than predicted by the model. About $72 \%$ of platform prices were lower than predicted by the model, compared to about $57 \%$ of market prices.

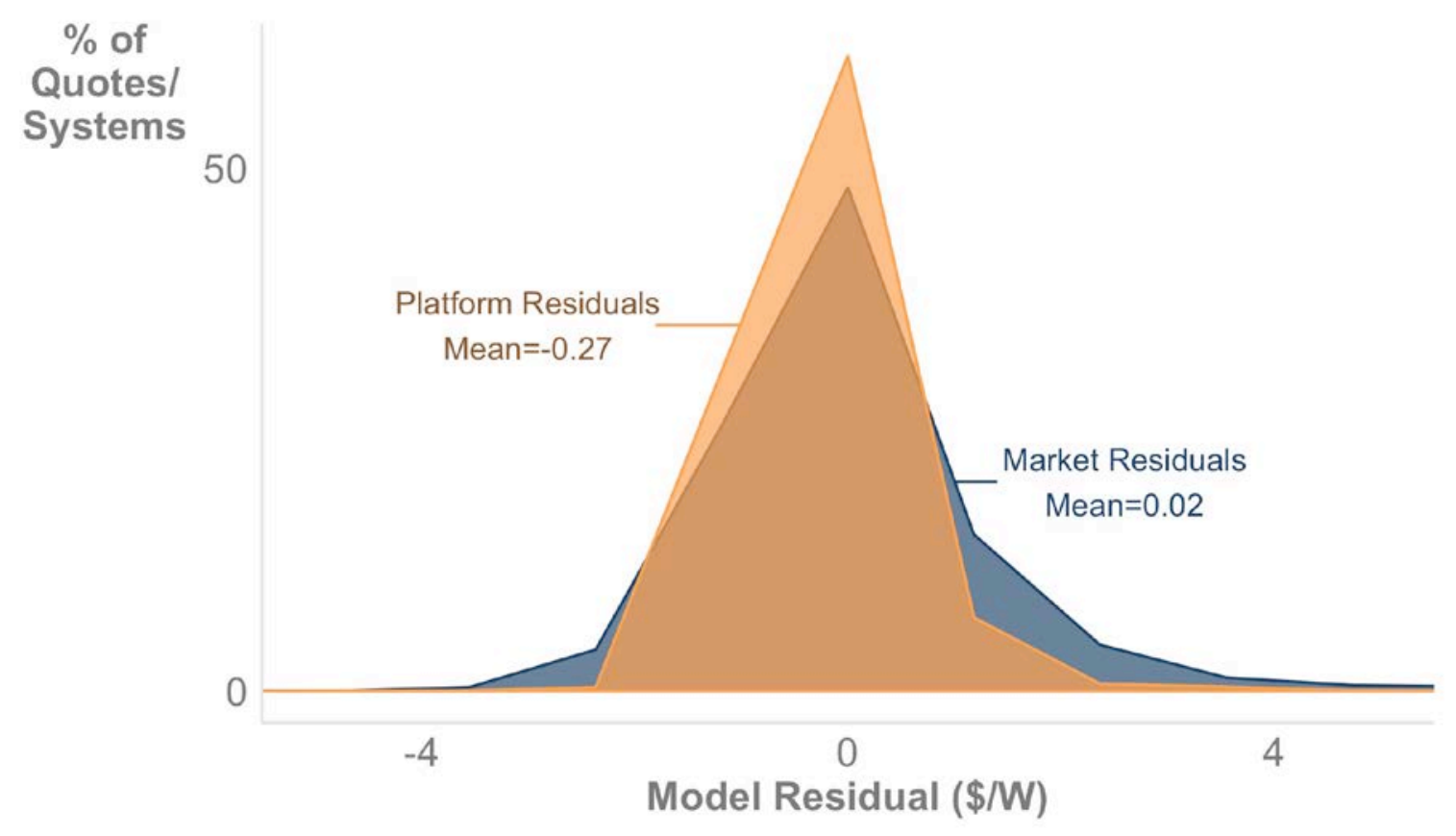

Figure 4. Distributions of platform and market residuals

One potential limitation of these results is that the regression model does not control for unobserved customer characteristics. Quote platform customers may vary in substantive ways from customers who obtain quotes directly from installers. For instance, quote platform customers might be more informed about PV, which could affect the prices that installers offer on the Pick My Solar platform. In our previous study (O'Shaughnessy and Margolis 2018), we controlled for these factors by analyzing a subset of data for customers who received quotes through the EnergySage platform and directly from installers. For that subset, platform prices were about $\$ 0.24 / \mathrm{W}$ lower on average than prices in quotes received directly from installers, which is smaller than the estimated discount compared to market-wide prices. Those results suggest that at least some of the observed difference between platform prices and market-wide prices is due to spurious unobserved differences between quote platform customers and other customers.

Our current analysis shows that Pick My Solar platform prices are about $\$ 0.31 / \mathrm{W}$ lower on average than market-wide prices after controlling for other factors. From this result, we can reasonably infer that the same customer would obtain a lower price through the quote platform than directly from an installer, though not necessarily $\$ 0.31 / \mathrm{W}$ lower. From our two studies, roughly $\$ 0.20 / \mathrm{W}-\$ 0.40 / \mathrm{W}$ seems to be a plausible range for the quote platform discount. In other words, our research indicates that PV customers can save around $\$ 0.20 / \mathrm{W}-\$ 0.40 / \mathrm{W}$ by obtaining quotes through quote platforms rather than directly from installers. That discount equates to $\$ 1,000-\$ 2,000$ in savings for a typical 5-kW residential PV system. 


\section{Analysis of Battery Installation Bid Prices}

The U.S. residential battery market is small but growing quickly (GTM 2017a). Hardware costs of lithium-ion batteries - currently the most common chemistry for residential batteries - fell by about $73 \%$ from 2010 to 2016 (Curry 2017). However, installed battery prices have remained relatively stagnant (GTM 2017b). The disconnect between hardware costs and installed prices is attributable to soft costs, such as installation labor, and possibly to imperfect competition in nascent battery markets. Similar to the case of PV, battery customers might obtain lower prices by obtaining battery quotes through platforms such as Pick My Solar.

Pick My Solar provided data on more than 60 battery contracts signed from Q2 2017 through Q1 $2018 .^{3}$ About $76 \%$ of the battery quotes were made to customers who had also previously received quotes for PV on the platform. All battery quotes represent quotes for standalone battery system installations (i.e., not batteries installed at the same time as a PV system).

Battery sizes are reported in terms of energy storage capacity $(\mathrm{kWh})$ or power output capacity $(\mathrm{kW})$. We report all battery sizes in $\mathrm{kWh}$ and normalize prices according to $\mathrm{kWh}(\$ / \mathrm{kWh})$. Battery sizes range from $4 \mathrm{kWh}$ to $39.6 \mathrm{kWh}$, with an average capacity around $15 \mathrm{kWh}$ (Figure 5). A typical U.S. home uses around $30 \mathrm{kWh}$ of electricity per day, so a fully charged 15 kWh battery could meet about $50 \%$ of the daily electricity demand for a typical home. This level of storage would allow for peak shifting, which would increase the value of a PV-plus-battery system under time-of-use or peak demand charge rate structures.

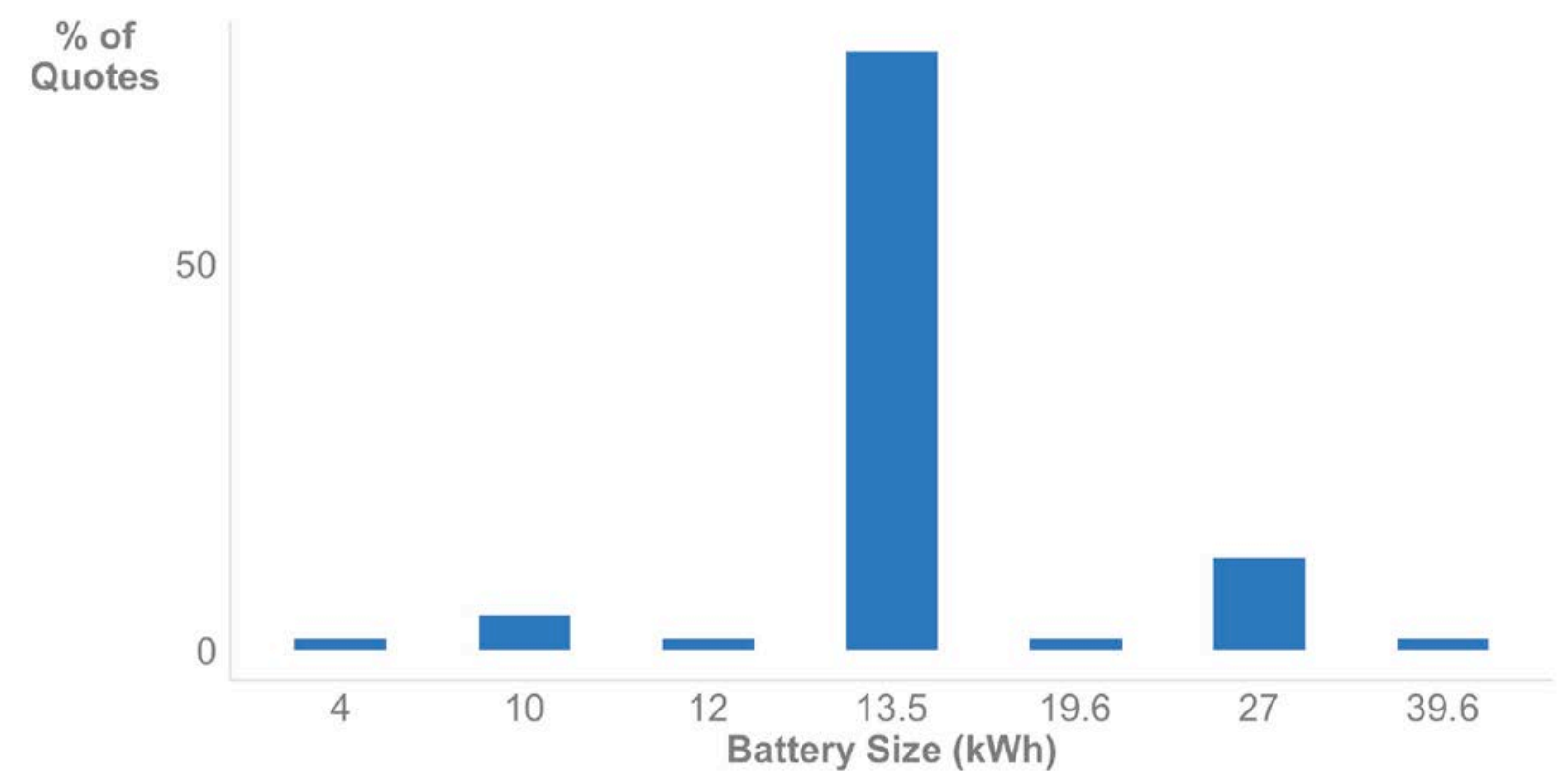

Figure 5. Distribution of battery sizes in data set

The $\mathrm{x}$-axis is not continuous.

Battery bid prices range from $\$ 640 / \mathrm{kWh}$ to $\$ 2,510 / \mathrm{kWh}$. About $78 \%$ of quotes fall between $\$ 740 / \mathrm{kWh}$ and $\$ 850 / \mathrm{kWh}$, with a cluster of quotes priced at $\$ 820 / \mathrm{kWh}$ (Figure 6 ). The fact that

${ }^{3}$ The precise sample size is not disclosed for proprietary reasons. 
quote prices appear to cluster around certain price points suggests that installers may standardize their offers to some extent; that is, battery installers may have a standard installation offer price for a given battery technology that does not vary from customer to customer. This contrasts with quotes for PV systems, which typically require customization depending on roof layout, size, conditions, and so forth.

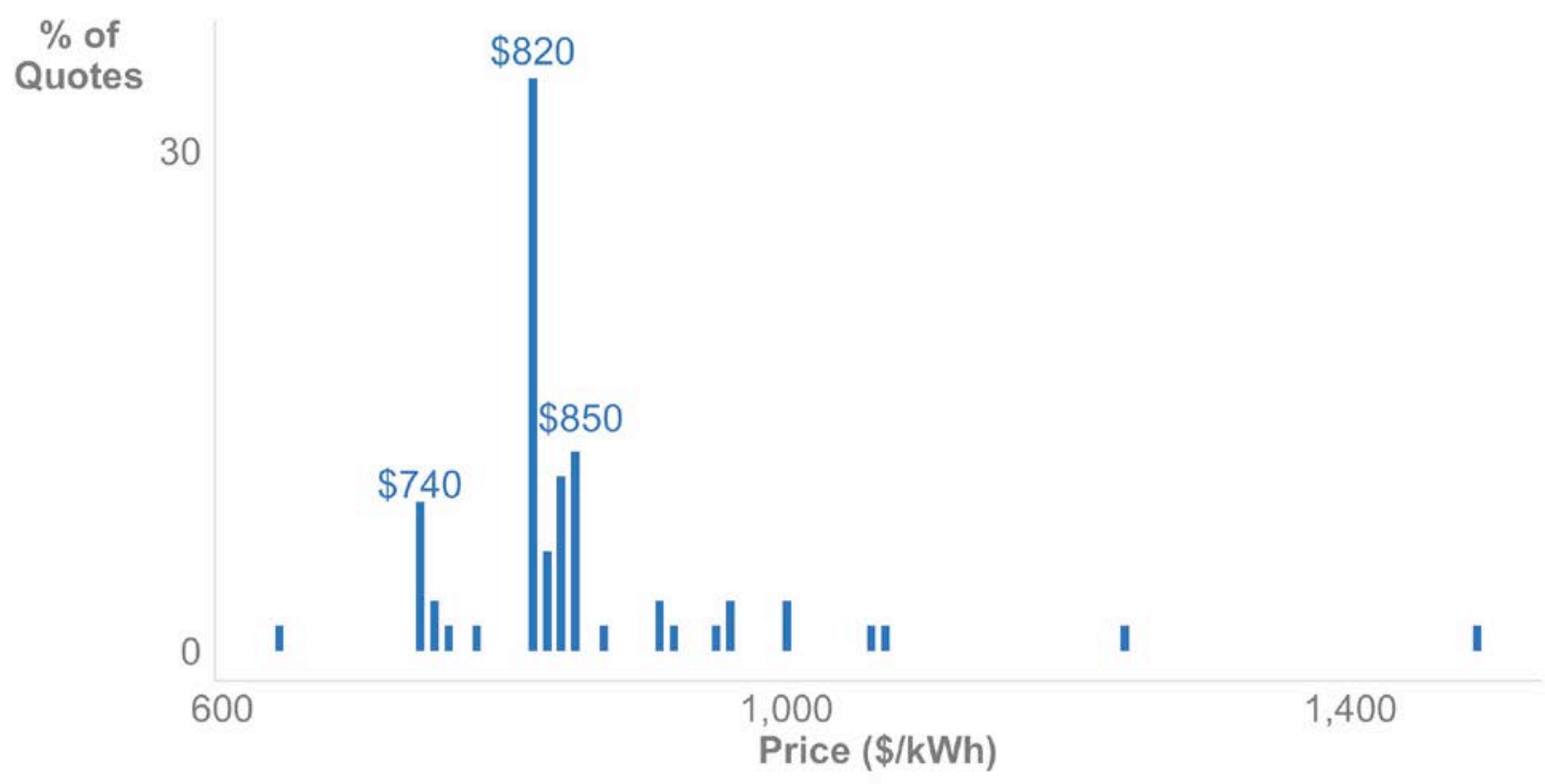

Figure 6. Battery quote price distribution

One outlying quote $(\$ 2,510 / \mathrm{kWh})$ is omitted.

Consistent with observations from GTM (2017b), battery quote prices on the quote platform appear stagnant over time (Figure 7). Average prices have hovered around $\$ 880 / \mathrm{kWh}$ in every quarter except Q3 2017, which exhibited a temporary drop in battery quote prices. 


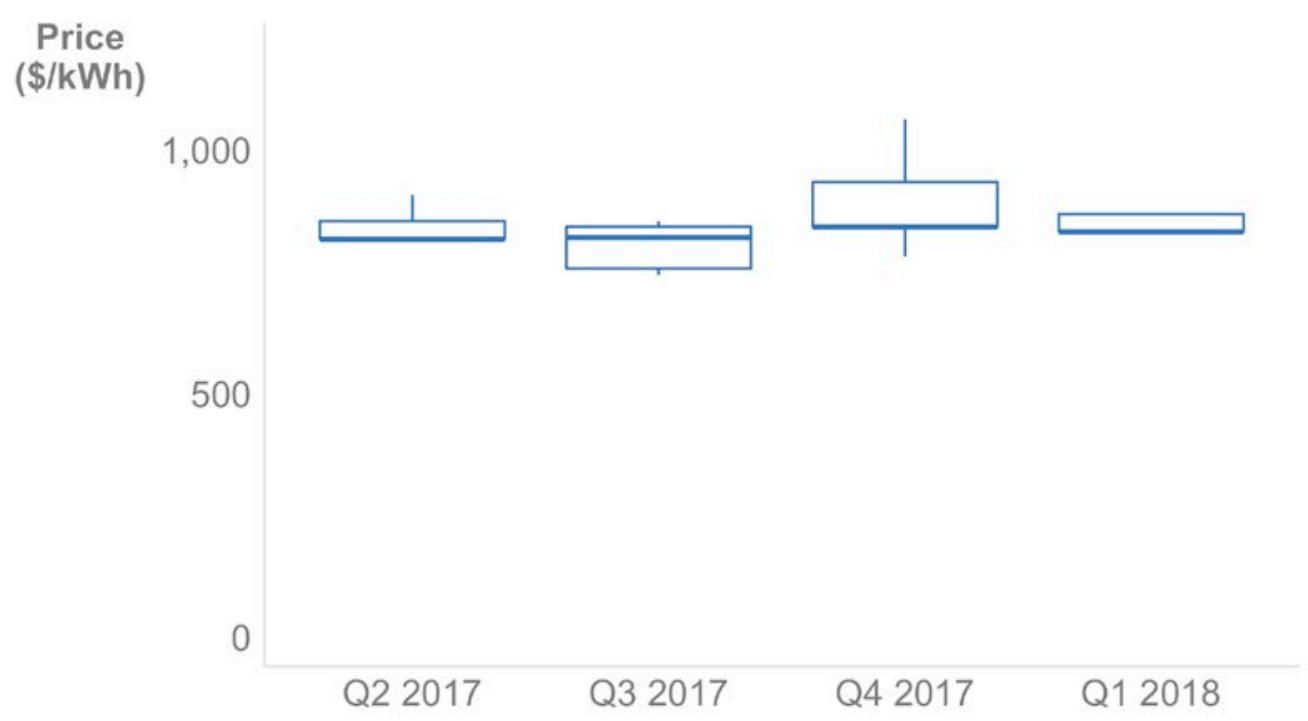

Figure 7. Battery quote price distributions by quarter

Boxes represent inter-quartile ranges $\left(25^{\text {th }}\right.$ to $75^{\text {th }}$ percentile), with medians depicted as horizontal lines within the boxes.

There is currently no comprehensive battery data set comparable to TTS that would allow us to replicate the analyses in Section 3 for batteries. The closest applicable points of comparison are ongoing installed price estimates provided by GTM (2017b). GTM estimates that installed battery prices in Q4 2017 ranged from $\$ 1,050 / \mathrm{kWh}$ to $\$ 2,000 / \mathrm{kWh}$, with a median of $\$ 1,500 / \mathrm{kWh}$. About $93 \%$ of the Pick My Solar battery quotes fall below GTM's low estimate, and about $98 \%$ of quotes fall below GTM's median estimate (Figure 8).

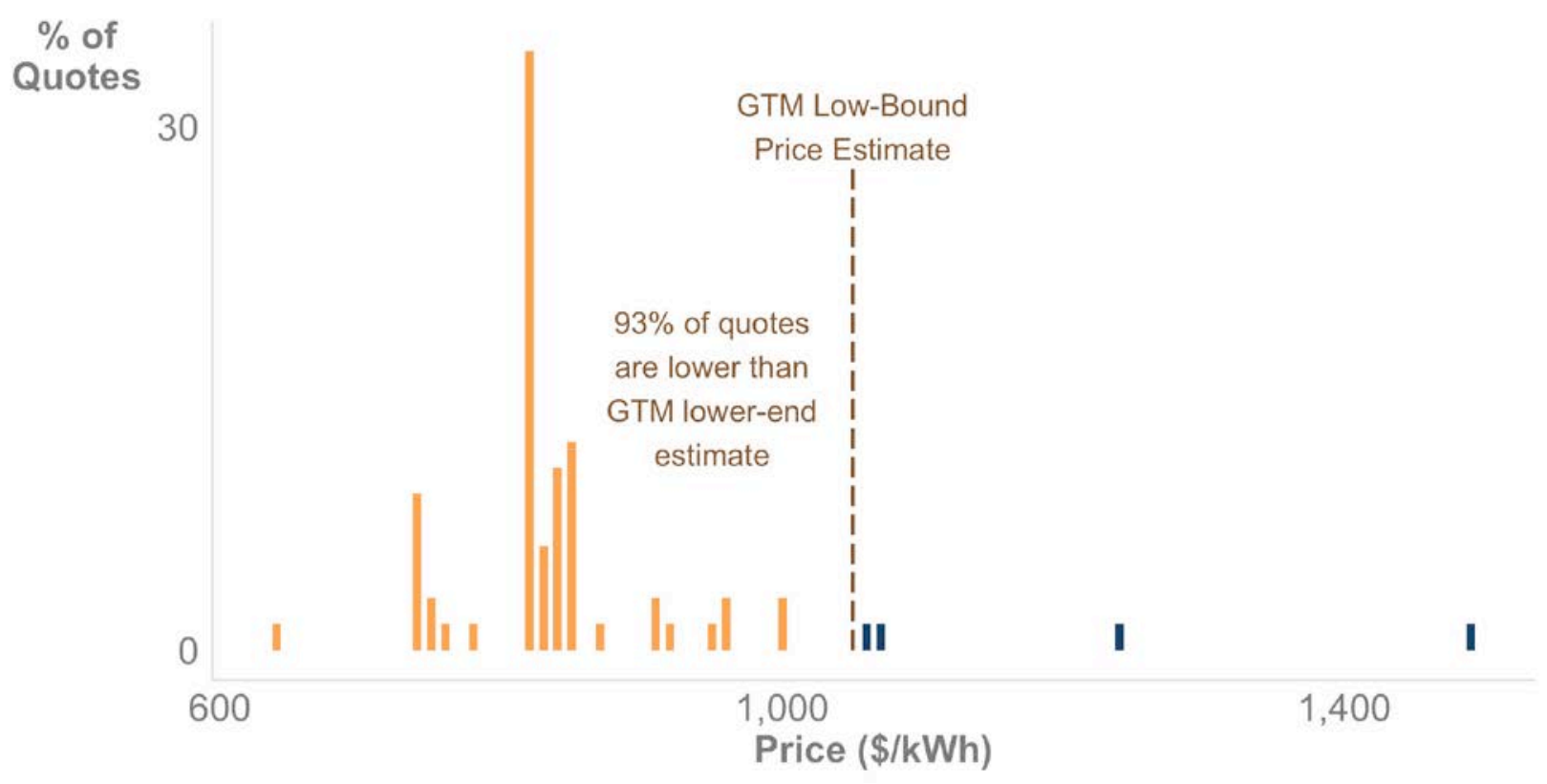

Figure 8. Pick My Solar battery quote distributions versus GTM low installed price estimate

Though the sample size is small and there may be confounding factors, the Pick My Solar battery quote data suggest that battery prices from quote platforms may be lower than market-wide 
prices. This early result indicates that quote platforms may provide a pathway to installed price reductions for batteries as well as PV systems. As battery sales increase on quote platforms, future work could re-examine this question with larger sample sizes and controlling for more factors. 


\section{Pathways toward Increased Use of Quote Platforms}

The results from this study and previous work based on a different quote platform suggest that competitive bidding on online quote platforms could drive PV price reductions. Despite their apparent benefits, quote platform use remains low. In 2017, about $3 \%$ of residential PV sales occurred through online quote platforms (Mond 2017), ${ }^{4}$ suggesting that more than $90 \%$ of customers obtained quotes directly from installers and likely paid higher prices than could have been obtained through a platform. In this section, we qualitatively explore four pathways that could increase the use of platforms and thus accelerate the associated price reductions and deployment. The discussion in this section is based on literature that provides context to the datadriven results provided in Sections 3 and 4, but we do not provide any further data analysis.

\subsection{Strategic Partnerships}

Quote platforms face a particular type of chicken-and-egg challenge: customers will only use quote platforms that allow customers to obtain quotes from many firms, while firms will only bid on quote platforms that allow firms access to many customers. Bakos (1991) refers to this challenge as a network effect in which the benefits to quote platform customers/bidders increase as more parties on both sides join the platform. Attracting firms to quote platforms is generally more challenging than attracting customers is. Because quote platforms tend to reduce profit margins, firms have incentives to avoid quote platforms (Bakos 1997). Hence attracting customers to quote platforms is likely to be a more practical and effective approach to generating network effects.

Customer acquisition is a challenge in the PV market overall (Mond 2017). Part of this challenges stems from relatively low levels of customer trust in PV installers and PV industry trade organizations (Moezzi et al. 2017; Reeves et al. 2017). It is unclear whether customers will trust quote platforms more, at least in the near term while the platforms work to establish reputability.

Because of their distrust of the PV installation industry, prospective customers generally seek objective information from sources, such as utilities, local government entities, and environmental organizations, with which they have preexisting relationships (Moezzi et al. 2017; Reeves et al. 2017). Strategic partnerships between these third-party organizations and quote platforms could provide a pathway to attract more customers to quote platforms. Utilities, local government entities, and environmental organizations could incorporate quote platforms into their own websites. The partner would benefit from providing a practical resource to stakeholders who are interested in PV adoption. The quote platform would benefit from the validation of a trusted partner and access to more prospective customers. This third-party validation may be particularly important for customers who are less comfortable with making online transactions (Beldad et al. 2010). Strategic partnerships could also help quote platforms incorporate local incentives into their quote platforms. For instance, quote platforms could automatically incorporate local rebates into the quote estimates posted on the platform.

\footnotetext{
${ }^{4}$ According to Mond (2017), about 3\% of PV sales occurred on quote platforms in 2017. However, many prospective customers use quote platforms without actually adopting PV, and an unknown number of customers use platforms to learn about PV prices but ultimately accept a quote received directly from an installer.
} 
Both Pick My Solar and EnergySage have formed partnerships with electric utilities. Under such partnership structures, utility customers who seek information about PV from a utility website are channeled to the quote platform (Figure 9). The utility partner may simply provide a link directing customers to the platform. Alternatively, the utility partner may incorporate the platform into its own website, such that the user interface remains consistent from the utility to the platform.

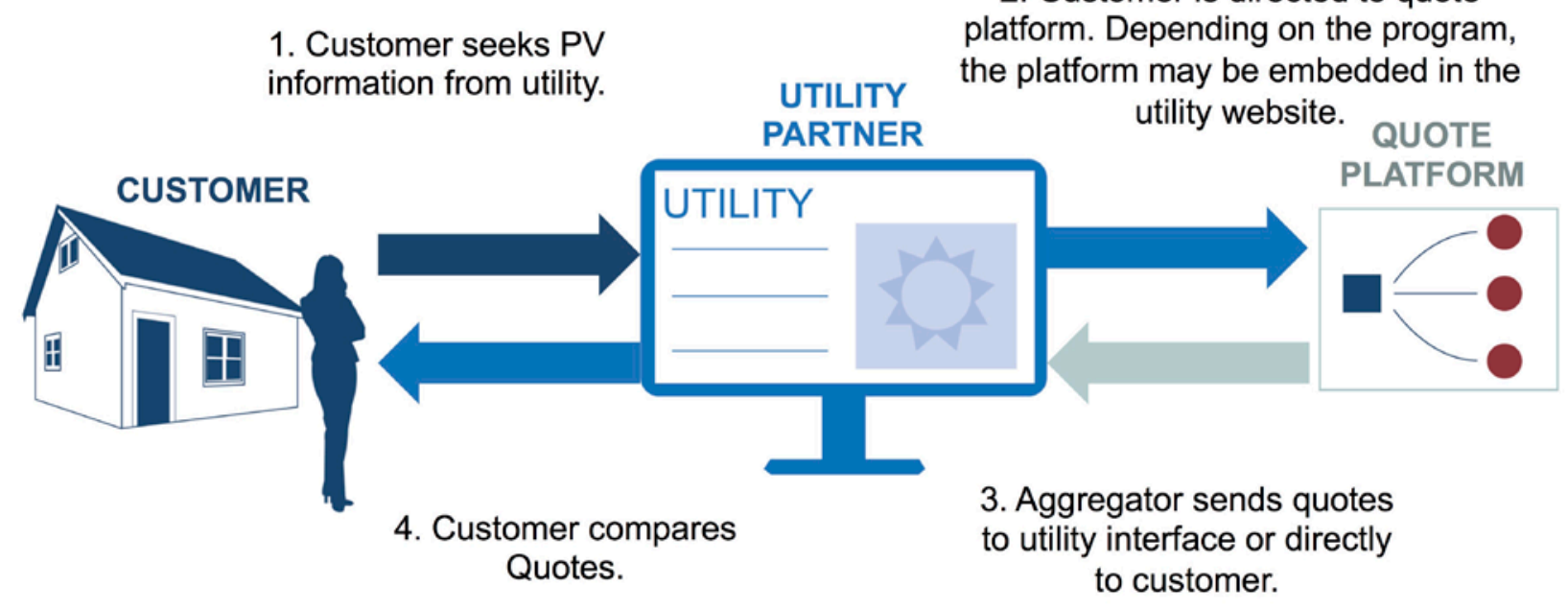

Figure 9. Quote platform/utility partnership structure

Structures may vary by program. The quote platform may be embedded within the utility website, so that the customer may be directed to the platform without actually leaving the utility website.

Solarize campaigns may be another viable partner for quote platforms. In a Solarize campaign, a community organization contracts with a PV installer or group of installers on behalf of the residents of some community. ${ }^{5}$ Solarize campaigns can yield lower prices through bulk purchasing and can help some customers navigate the PV-adoption process more comfortably. Rather than contract directly with an installer or group of installers, Solarize campaigns may instead work with quote platforms to mediate the transactions. The quote aggregator could work with a subset of its installer network that is willing to install systems in the Solarize community. The Solarize customers could then solicit and collect bids via the platform. Such a partnership could simultaneously leverage the price-reducing effects of quote platforms and Solarize campaigns, although it is unclear whether the two effects are additive. For instance, Pick My Solar has partnered with various Solarize campaigns. Pick My Solar reports that the prices from the campaigns were lower than their typical platform prices. Potential synergies between quote platforms and Solarize campaigns are an area for further research.

\subsection{Building of Customer Trust}

Establishing customer trust is a key challenge for successful online marketplaces such as quote platforms (Hoffman et al. 1999; Gefen 2000; Ba and Pavlou 2002; Flavian et al. 2006; Urban et al. 2009; Beldad et al. 2010; Ingham et al. 2015). Customer trust is an important issue in all

\footnotetext{
${ }^{5}$ For more information about Solarize campaigns, see "Solarize Guidebook," U.S. Department of Energy, https://www.energy.gov/eere/solarpoweringamerica/solarize-guidebook.
} 
economic transactions but is especially important for online transactions. Online transactions are "faceless and intangible" (Beldad et al. 2010), meaning customers may never have an in-person interaction during the process. Online transactions require trust not only in the company providing the product, but also in a third party mediating the transaction (e.g., a quote aggregator). Online transactions also entail additional security and privacy concerns that may not be present in faceto-face interactions.

Customer trust is a key factor in PV adoption, especially in terms of installer trustworthiness (Rai et al. 2016; Moezzi et al. 2017; Reeves et al. 2017). PV customers must trust that their preferred installer will do quality work, charge a fair price, and be available in the future to service a warranty, among other factors. Rai et al. (2016) find that interactions with installers help establish this trust: customers in that study generally reported that interactions with installers improved the customers' confidence and motivated them to adopt. Bringing PV transactions online may increase the complexity and the importance of PV customer trust. On one hand, by removing or reducing opportunities for in-person interactions with installers, online quote platforms could potentially reduce PV customer trust during the adoption process. On the other hand, quote platforms may increase customer trust by allowing customers to compare multiple quotes on common terms. Further research is required to determine how online quote platforms affect PV customer trust and how quote platforms could be designed to increase customer trust.

Beldad et al. (2010) identify seven factors that can improve online customer trust (Table 2). In addition, Beldad et al. (2010) note that quote platform companies can build trust and reputation through an offline presence. Through the so-called "brick-and-click" approach, web-based companies offer online services backed by a physical offline presence. For instance, PV quote platforms could establish customer-facing offices with in-person consulting services. At scale, quote platforms could have multiple physical offices located in major PV markets. Though the brick-and-click approach could improve customer experiences, it could also increase quote platform costs and ultimately reduce some of the potential cost savings from platform bidding. 
Table 2. Factors that Determine Customer Trust in Online Transactions ${ }^{a}$

\begin{tabular}{|c|c|}
\hline Trust Factor & Description \\
\hline Ease of use & $\begin{array}{l}\text { Users trust platforms more when they are easy to navigate and have } \\
\text { easy-to-use features such as search functions, site maps, and product } \\
\text { indices. }\end{array}$ \\
\hline Information quality & $\begin{array}{l}\text { Users trust platforms more when information is useful, accurate, and } \\
\text { complete. Users require detailed and clear information in online } \\
\text { transactions as a substitute for the "touch-and-feel" aspects of face-to- } \\
\text { face transactions. }\end{array}$ \\
\hline Graphical characteristics & $\begin{array}{l}\text { The aesthetics of the platform and related web interfaces can affect } \\
\text { customer trust. Interfaces should be professional and aesthetically } \\
\text { pleasing. }\end{array}$ \\
\hline Social presence & $\begin{array}{l}\text { Users feel more trust in online transactions that replicate in-person } \\
\text { transactions through social presence: the degree to which a web } \\
\text { interface conveys a feeling of connection with a real person. Social } \\
\text { presence can be increased through features such as live chats, } \\
\text { human web assistants, and message boards. }\end{array}$ \\
\hline Customization & $\begin{array}{l}\text { Users trust platforms more when the web interfaces are customized } \\
\text { for the target users. }\end{array}$ \\
\hline Privacy and security & $\begin{array}{l}\text { Strict privacy policies and enhanced transaction security features can } \\
\text { increase customer trust. }\end{array}$ \\
\hline Third-party guarantees & $\begin{array}{l}\text { Validations from trusted third parties can increase consumer } \\
\text { confidence in platforms, especially during startup periods when } \\
\text { platforms have no transactional history. }\end{array}$ \\
\hline
\end{tabular}

a Based on a review of studies in Beldad et al. (2010)

For instance, to establish customer trust, Pick My solar assigns an Energy Advisor to every customer who uses the platform. The Energy Advisors help customers navigate the entire process. After the transaction is completed, Pick My Solar's Customer Success department stays involved with the project to ensure the installation process moves forward and mediates any potential dispute between customers and installers. Pick My Solar reports that this level of support leads to higher customer satisfaction.

\subsection{Market Transparency}

PV markets are nontransparent, meaning customers lack easy access to information about prices, products, and installers. Quote platforms could play a role in improving market transparency. Quote aggregators could use their platforms to provide various informational resources about PV adoption, including fair market prices, steps in the adoption process, and information about installers. By increasing market transparency, quote aggregators could attract more customers to quote platforms, improve customer confidence in PV adoption, and potentially drive increased PV deployment. 
Quote aggregators have already implemented various measures to improve market transparency. For instance, the Pick My Solar and EnergySage websites provide educational resources about the PV adoption process. Pick My Solar hosts a video library and conducts live streams to educate customers on various topics and answer prospective customer questions in real time. EnergySage provides information about all the installers in its installer network.

\subsection{Quality Guarantees}

$\mathrm{PV}$ adoption entails several risks, including risks that the system will underperform, require maintenance, or damage the home. The PV industry has developed various measures to mitigate risks and allay customer concerns, such as certifications, installer insurance, and product warranties. Quote aggregators could further reduce risk by serving as guarantors of quality. They could set minimum levels of certifications, insurance, and warranties for bids posted to the platform, and they could act as guarantors on warranties in the event of an installer default (e.g., due to installer bankruptcy).

Quote platforms have already implemented quality-guarantee measures. Pick My Solar and EnergySage both require all installers to be fully insured and certified by the North American Board of Certified Energy Practitioners and to have at least three years of PV installation experience. Further, Pick My Solar guarantees that the installed system will generate at least $95 \%$ of the estimated output; otherwise, Pick My Solar reimburses the customer for the estimated reduction in projected cost savings. 


\section{Discussion and Conclusion}

The results of this study — along with results from O'Shaughnessy and Margolis (2018) — provide evidence that customers receive lower PV prices on quote platforms than when soliciting quotes directly from installers. PV customers might save roughly $\$ 0.20 / \mathrm{W}-\$ 0.40 / \mathrm{W}$ by using quote platforms, which is equivalent to $\$ 1,000-\$ 2,000$ in savings for a typical $5-\mathrm{kW}$ residential PV system.

Customers increasingly have been using quote platforms to obtain PV prices, and continued growth of platform use could yield PV price reductions for at least two reasons. First, it could push the average PV price point toward platform prices, which tend to be $\$ 0.20 / \mathrm{W}-\$ 0.40 / \mathrm{W}$ lower than other prices. Second, it could produce spillover effects by forcing reductions in quotes obtained outside platforms. For instance, national-scale installers - which have not historically bid on quote platforms - may be forced to offer lower prices if enough prospective customers begin to use the platforms. As quote platforms expand, future research may explore how their growth affects PV bids obtained outside the platforms.

Our study also provides one of the first explorations of installed battery price data. We find evidence that battery prices from quote platforms are lower than market-wide prices, though the sample size is small, and we are currently unable to control for other potentially confounding factors; further research is required. In addition, the data suggest that installed battery prices are not falling as quickly as battery hardware costs. Further, the data suggest installed battery prices may be more standardized than installed PV prices. Future research might investigate the factors that drive variation in installed battery prices - such as site characteristics, local labor costs, and local market competition — similar to how PV price dispersion has been studied.

Collectively, these results suggest that quote platforms provide a pathway for ongoing PV and battery price reductions. Various approaches could increase the use of platforms and thus accelerate the associated price reductions and deployment. These approaches include forming strategic partnerships between platforms and trusted third parties (e.g., utilities, local government entities, environmental organizations, and Solarize campaigns), building customer trust in online and "brick-and-click" platform interfaces, using platform features to enhance PV market transparency, and offering quality guarantees through platforms.

Finally, though our study focuses on the demand-side effects of quote platforms, platforms have potential supply-side impacts as well. First, increased competition and reduced prices generally imply reduced installer profit margins. Indeed, several installers report tighter margins on quote platforms, which are not always offset by sales increases (O’Shaughnessy and Margolis 2017). Second, in part because of reduced margins, increased activity on quote platforms could redistribute market shares among competing installers. On one hand, quote platforms are generally used by local mid-scale installers, such that increased platform activity could shift market shares from high-volume national-scale installers to local installers. On the other hand, both EnergySage and Pick My Solar have eligibility criteria that exclude new and very smallscale installers. These criteria may make it more difficult for new installers to compete and scale up, effectively creating a barrier to market entry. The supply-side impacts of quote platforms are another area for future research. 


\section{References}

Ba, S., and P. Pavlou. 2002. "Evidence of the Effect of Trust Building Technology in Electronic Markets: Price Premiums and Buyer Behavior.” MIS Quarterly 26(3): 243-268.

Bakos, J. 1991. “A Strategic Analysis of Electronic Marketplaces.” MIS Quarterly 15(3): 295310.

Bakos, J. 1997. "Reducing Buyer Search Costs: Implications for Electronic Marketplaces." Management Science 43(12): 1676-1692.

Barbose, G., and N. Darghouth. 2017. Tracking the Sun 10: The Installed Price of Residential and Non-Residential Photovoltaic Systems in the United States. Berkeley, CA: Lawrence Berkeley National Laboratory.

Beldad, A., M. Jong, and M. Steehouder. 2010. "How Shall I Trust the Faceless and Intangible? A Literature Review on the Antecedents of Online Trust." Computers in Human Behavior 26: 857-869.

Brynjolfsson, E., and M. Smith. 2000. "Frictionless Commerce? A Comparison of Internet and Conventional Retailers." Management Science 46(4): 563-585.

Curry, C. 2017. Lithium-ion Battery Costs and Market. Bloomberg New Energy Finance.

EnergySage. 2018. Solar Installer Survey 2017 Results.

Flavián, C., M. Guinalíu, R. Gurrea. 2006. “The Role Played by Perceived Usability, Satisfaction, and Consumer Trust on Website Loyalty." Information \& Management 43: 1-14.

Gefen, D. 2000. "E-commerce: The Role of Familiarity and Trust.” Omega 28: 725-737.

GTM. 2017a. U.S. Energy Storage Monitor: Year in Review. GTM Research.

GTM. 2017b. U.S. Energy Storage Monitor: Q4 2017. GTM Research.

Hoffman, D., T. Novak, and M. Peralta. 1999. "Building Consumer Trust Online." Communications of the ACM 42(4): 80-85.

Ingham, J., J. Cadieux, and A. Berrada. 2015. “e-Shopping Acceptance: A Qualitative and Metaanalytic Review." Information \& Management 52: 44-60.

Leibowicz, B., E. O’Shaughnessy, K. Punjabi, and R. Margolis. 2018. Effects of Platform Design on the Customer Experience in an Online Solar PV Marketplace. NREL/TP-6A20-71178.

Golden, CO: NREL.

Moezzi, M. A. Ingle, L. Lutzenhiser, and B. Sigrin. 2017. A Non-Modeling Exploration of Residential Solar Photovoltaic (PV) Adoption and Non-Adoption. NREL/SR-6A20-67727. Golden, CO: NREL. 
Mond, A. 2017. U.S. Residential Solar PV Customer Acquisition 2017. GTM Research.

Nemet, G., E. O'Shaughnessy, R. Wiser, N. Darghouth, G. Barbose, K. Gillingham and V. Rai. 2017. "Characteristics of Low-priced Solar PV Systems in the United States." Applied Energy 187: 501-513.

O'Shaughnessy, E. 2018. The Effects of Market Concentration on Residential Solar PV Prices: Competition, Installer Scale, and Soft Costs. NREL/TP-6A20-71296. Golden, CO: NREL.

O'Shaughnessy, E., and R. Margolis. 2017. The Value of Transparency in Distributed Solar PV Markets. NREL/TP-6A20-70201. Golden, CO: NREL.

O’Shaughnessy, E., and R. Margolis. 2018. "The Value of Price Transparency in Residential Solar Photovoltaic Markets.” Energy Policy 117: 406-412.

O’Shaughnessy, E., D. Cutler, K. Ardani, and R. Margolis. 2018. "Solar Plus: A Review of the End-user Economics of Solar PV Integration with Storage and Load Control in Residential Buildings." Applied Energy 228: 2165-2175.

Perea, A., C. Honeyman, A. Mond, C. Smith, M. Davis, MJ. Shiao, J. Jones, S. Moskowitz, and B. Gallagher. 2017. U.S. Solar Market Insight: 2017 Year in Review. GTM Research.

Rai, V., D. Reeves, and R. Margolis. 2016. "Overcoming Barriers and Uncertainties in the Adoption of Residential SPV." Renewable Energy 89: 498-505.

Reeves, D., V. Rai, and R. Margolis. 2017. "Evolution of Consumer Information Preferences with Market Maturity in Solar PV Adoption.” Environmental Research Letters 12074011.

Urban, G., C. Amyx, and A. Lorenzon. 2009. "Online Trust: State of the Art, New Frontiers, and Research Potential.” Journal of Interactive Marketing 23: 179-190. 